\title{
微重力环境下 InSb 晶体生长
}

\author{
张仿清 张 莉 陈光华 沈朚智 晏国洪 \\ (兰州大学物理系)
}

达道安黄良甫谢䇾谈晓臣

（兰州物理研究所）

\section{关篗调 InSb 品体生长、微重力、杂质条纹}

近年来,空间材料加工引起了人们极大兴趣. 我国首次利用 1987 年 8 月 5 日发射的返回 式卫星在空间微重力环境下进行了材料加工实验．在此次实验中，用定向正常㷷固法对 InSb 单晶材料进行了重熔和再结晶. 这次实验的特点是: 采用了多用途晶体加工炉, 炉的中间安 放 $\mathrm{GaAs}$ 材料, InSb 样品放在炉内一侧, 同时还在炉内不同位置安装了其它材料, 这种在一 妒内同时完成多种材料加工我们尚未见到报道. 关于晶体加工在卫星上通电工作期间的微重 力水平、估算值优于 $2 \times 10^{-4} \mathrm{~g}$ ( $\mathrm{g}$ 是地湎标准重力加速度 $)$.

我们先把在地面上沿 $\left\langle 111\right.$ 〉方向生长的掺 $\mathrm{Zn}$ 的 $\mathrm{InSb}$ 单晶(掺杂浓度约为 $\sim 10^{16} / \mathrm{cm}^{3}$ ) 切 成长 $5 \mathrm{~cm}$ 的方形晶棒, 在 $1.33 \times 10^{-3} \mathrm{~Pa}$ 真空度下封人清洁过的石英管内, 然后将封好的石英 管置于多用途单晶生长炉内一侧. 在空间, 加热时间为 $90 \mathrm{~min}$, 然后自然冷却. 为了便于比较, 用同一锭条上切下的 $I n S b$ 单晶, 在同一加工炉内以同样的温度条件在地面上进行了模似实验.

\section{一、实验结果和讨论}

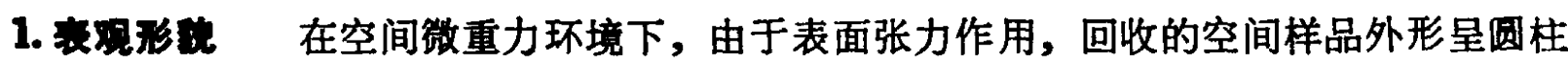
状，圆柱直径均匀，样品表面平滑. 样品与石英管壁之间不粘，打开石英管之前样品可在石英 管内来回活动. 体现出样品与石英壁之间明显的不润湿效应. 而地面样品呈䢃状，热端扁而 宽, 且样品与石英管壁粘得很牢,表现出明显的重力效应. 由此看来，在微重条件下进行材料 加工可以避免材料受器壁的污染. 样品外形照片如图 1 所示.

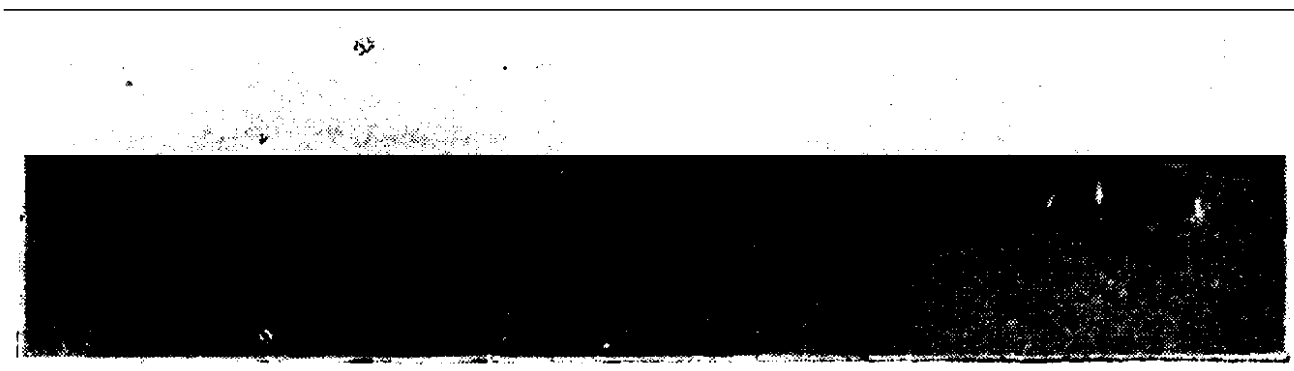

地面 太空

图 1 样品外形图

本文 1988 年 3 月 30 日收到. 
2. 杂夏条纹 对空间样品和地面样品分别沿生长方向用 $\mathrm{CP}-4$ 腐蚀剂 $\left(1 \mathrm{HF}+1 \mathrm{CH}_{3}-\right.$ $\left.\mathrm{COOH}+1 \mathrm{KMnO}_{4}\right)$ 腐蚀 $60 \mathrm{~s}$, 用 S-450 型扫描电镜观察其形貌, 发现地面样品存在明显的杂 质条纹，如图 $2 \mathrm{a}$ 所示,对空间样品各部位做了反复观察，均没有观察到杂质条纹，如图 $2 \mathrm{~b}$ 。
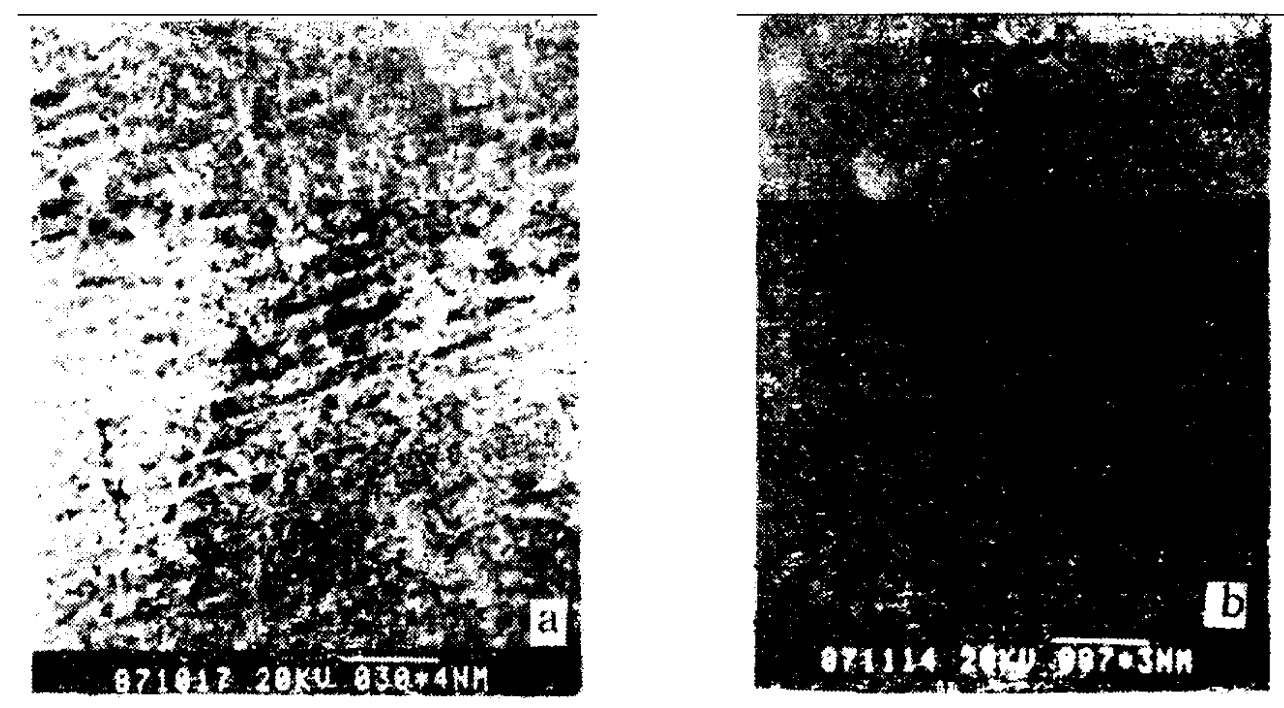

图 2 样品腐蚀后电镜照片

a. 地面样品； b. 空间样品

这是由于在地面进行晶体生长时, 重力和温度梯度的存在, 在熔体中会产生热对流, 这种 对流造成固液界面的温度涨落, 因而使晶体生长速率也产生涨落, 生长速率的胀落进一步导致 杂质的微分凝，因此样品经腐蚀能观察到明显的生长条纹. 金刚等 ${ }^{[1}$ 曾对地面生长的 InSb 晶 体的(111)面,(211) 面进行观察均有杂质条纹存在. 在空间微重力环境下, 重力驱动的热对流 消失, 即产生杂质条纹的主要原因不存在了, 故空间样品没有观察到杂质条纹. Witt 等人在 M652 工作中也得到同样的结果 ${ }^{[2]}$.

3. X 射线衍射和电子衍射分析 把不同位置的空间样品分别在 $E M-400 \mathrm{~T}$ 型分析电 镜上作了电子衍射实验, 得到对称性很好的立方晶系单晶衍射点. 同时又在 JPE X射线晶 体分析仪上作了 $\mathrm{X}$ 射线背射劳厄实验, 其衍射点成三度对称, 其极射赤投影图基本上与 (111)面标准图对应, 这表明晶体生成方向基本上沿〈111〉方向, 但还存在一小的偏差, 这个偏 差可能是由于切片不准造成的.

4. 电阻事测试用单探针法分别对空间样品和地面样品的横剖面沿径向进行了电阻率

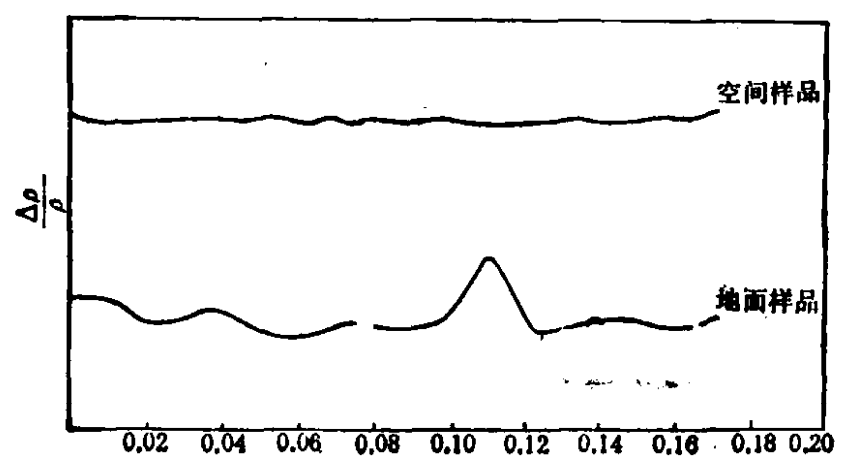

图 3 电阻率相对变化图 
的测至, 每隔 $0.1 \mathrm{~mm}$ 测一个点. 电阻种的相对变化用 $\frac{\Delta \rho}{\rho}$ 来表示, $\Delta \rho$ 为所测电阻率最大俻 与最小值之差， $\boldsymbol{\rho}$ 为所测电阻率的平均值. 空间样品电阻率的相对变化为 $3.6 \%$, 而地面样品 为 $34 \%$. 电阻率的相对变化如图 3 所示. 从此结果可以看出空间样品电阻率的均匀性提高了 很多,这部进一步证明了空间微重力环境下晶体的掺杂均匀性提高了 ${ }^{[3]}$.

综上所述,在空间钽重力环境下,如果很好控制晶体生长条件，能够得到较高质量的半导 体材料。

\section{$\geqslant$ 辛 文}

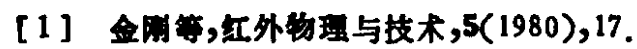

[2] Witt, A. F. et al., J. Electrochem. Soc, 122(1975), 276.

[3] Benz, K. W. and Nagel. G, Proc. 5th European Symp on Material Sciences Under Microgravity, Schloss Elmau. ESA SP-222, 1984, 157. 